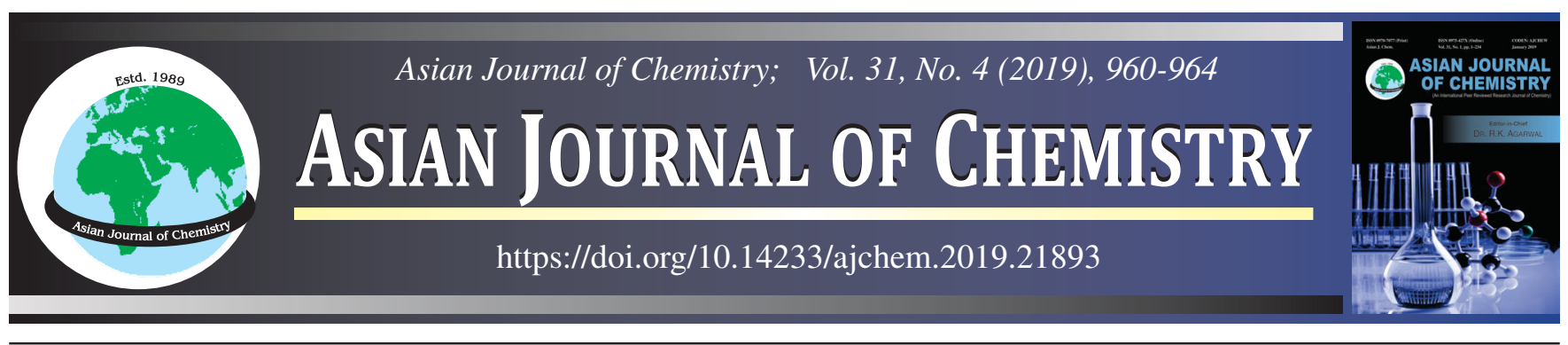

\title{
Ultrasonic Studies on the Nature of Molecular Interaction of Synthesized Mannich Bases in DMSO at Different Temperatures
}

\section{S. Farook Basha* and M. Syed Ali Padusha}

Post Graduate and Research Department of Chemistry, Jamal Mohamed College (Autonomous), Tiruchirappalli-620020, India

*Corresponding author: Tel: +91 431 2331135; E-mail: drfarookbasha@gmail.com

Received: 23 December 2018;

Accepted: 25 January 2019;

Published online: 27 February 2019;

AJC-19312

This work deals with the ultrasonic studies of the Mannich bases (morpholin-4-yl)(pyridin-3-yl)methyl]hydrazine carboxamide (MPH) and (morpholino)(thiophen-2-yl)methyl)nicotine hydrazide (MTN) by the measurements of parameters such as ultrasonic velocity (U), density $(\rho)$, viscosity $(\eta)$, adiabatic compressibility $(\kappa)$, intermolecular free length $\left(\mathrm{L}_{\mathrm{f}}\right)$, molar volume $\left(\mathrm{V}_{\mathrm{m}}\right)$, relaxation time $(\tau)$, specific acoustic impedance $(\mathrm{Z})$, lenard jones potential (LJP), internal pressure $\left(\pi_{\mathrm{i}}\right)$, free volume $\left(\mathrm{V}_{\mathrm{f}}\right)$ and molecular cohesive energy $(\mathrm{MCE})$, available volume $\left(\mathrm{V}_{\mathrm{a}}\right)$, Gibbs free energy $(\Delta \mathrm{G})$ and absorption coefficient $\left(\alpha / \mathrm{f}^{2}\right)$. These results are inferred that the strong interaction exists between the solvent (DMSO) and solute (MPH and MTN).

Keywords: Ultrasonic, Ultrasonic velocity, Density, Viscosity, Mannich bases.

ᄂ - - - - - - - - - - - - - - - - - - - - - - - - - - -

\section{INTRODUCTION}

Ultrasonics or ultrasound is an area of extreme scientific and technological research. The scientific administering of ultrasonics has drawn attention of researchers. Recent developments in science and technology of ultrasonics in molecular mutual actions are extremely impressive and hold worthy of consideration possibilities for more suitable applications. In modern years, ultrasonics velocity measurement methods finds comprehensive applications in studying the molecular mutual action to have actual being through liquid mixtures. These methods has made an interest to take into consideration of molecular interactions in pure binary and ternary liquids [1]. On account of the precise value of ultrasonic velocity measurements, they are used to deal the hypothetical situations of construction and molecular mutual action in liquids [2]. The ultrasonics or ultrasound measurement studies on estimation, ultrasonic and viscometric properties of multicomponent liquid mixtures have found wide applications in industries such as textile, chemical, leather and nuclear [3]. The study and understanding of thermodynamic and transport properties of liquid mixtures and solutions are more essential for their applications in these industries. The weak and strong molecular mutual actions present in the pure binary and ternary liquid mixtures can be detected and assessed by the use of ultrasonic velocity measurements $[4,5]$. By making an advantageous purpose of Bhat equation, stability constants and ultrasonics research of liquid mixtures were carried out [6-11]. These studies in multicomponent binary and ternary mixtures and solutions have been carried out by infrared, Raman effect, NMR and dielectric methods [12-15]. The nature and resistance of molecular mutual actions in the mixtures based on the variation of ultrasonic velocity and other related acoustical parameters with change in composition of the component of the pure liquids and can be utilized for the development of molecular models in order to describe the behaviour of solutions [16-18]. Earlier to ultrasonic employment to mixtures and solutions, the spectroscopic and dielectric skilled procedures were the only feature to study the nature and resistance of molecular mutual actions. However, the employment of ultrasonics has made possible not only the evaluation of physicochemical properties of the mixtures and solutions but also more reliability on the interpretation of molecular mutual actions. Due to the act of bringing low cost, easy operational procedure and spontaneous results, the molecular interaction studies through ultrasonics have gained importance all over the world. The compounds 2-[(morpholin-4-yl)(pyridin-3-yl)methyl]hydrazinecarboxamide (MPH) and (morpholino(thiophen-2-

This is an open access journal, and articles are distributed under the terms of the Creative Commons Attribution-NonCommercial-ShareAlike 4.0 (CC BY-NC-SA 4.0) International License which allows readers to freely read, download, copy, distribute, print, search, or link to the full texts of its articles and to use them for any other lawful non-commercial purpose as long as the original source is duly acknowledged. 
yl)methyl)nicotinohydrazide (MTN) are found to possess $\mathrm{N}-\mathrm{H}-\mathrm{CO}$ groups in its structure. This has been characterized by spectral studies. Denoting and signifying within molecular hydrogen bonding may entangle in the compounds, due to the state of $\mathrm{CO}$ and $\mathrm{NH}$. Based upon the evaluation and findings, the ultrasonics rate of motion, density and viscosity and their related ultrasonical measures of the synthesized compounds which contains the cluster of amide moieties have been presented.

\section{EXPERIMENTAL}

Accurately weighed amount of the synthesized compounds (MPH \& MTN) were dissolved in the solvent DMSO to obtain solution in the concentration range $1 \times 10^{-3}$ to $10^{-2} \mathrm{M}$. The ultrasonic velocities (U) have been measured in ultrasonic interferometer operating at a frequency of $2 \mathrm{MHz}$ with an accuracy of $\pm 0.1 \%$. The viscosities of the pure compounds and their mixtures were determined using Ostwald's viscometer calibrated with double distilled water. The densities of the solutions were measured accurately using $10 \mathrm{~mL}$ specific gravity bottles in an electronic balance precisely and the accuracy in weighing $\pm 0.1 \mathrm{mg}$. The temperature of the solutions and their mixtures was maintained at 303, 308 and $313 \mathrm{~K}$ using a thermostat. The acoustical parameters such as adiabatic compressibility $(\kappa)$, intermolecular free length $\left(\mathrm{L}_{\mathrm{f}}\right)$, molar volume $\left(\mathrm{V}_{\mathrm{m}}\right)$, relaxation time $(\tau)$, specific acoustic impedance $(\mathrm{Z}), \mathrm{LJP}$, internal pressure $\left(\pi_{\mathrm{i}}\right)$, free volume $\left(\mathrm{V}_{\mathrm{f}}\right)$ and molecular cohesive energy (MCE), available volume $\left(\mathrm{V}_{\mathrm{a}}\right)$, Gibbs free energy $(\Delta \mathrm{G})$ and absorption coefficient $\left(\alpha / \mathrm{f}^{2}\right)$ were measured [19-21].

The study of various acoustical parameters and the factors controlling the parameters helps to understand the structure of liquid systems.

\section{Ultrasonic velocity $(\mathbf{U})$ :}

$$
\mathrm{U}\left(\mathrm{m} \mathrm{s}^{-1}\right)=\mathrm{f} \lambda
$$

where, $\mathrm{f}$ - frequency of ultrasonic waves, $\lambda$ - wavelength.

Adiabatic compressibility ( $\boldsymbol{\beta})$ : From the measured values of the ultrasonic velocity $(\mathrm{U})$ and the density $(\rho)$, the adiabatic compressibility $(\beta)$ is calculated by using the relation:

$$
\beta\left(\mathrm{kg}^{-1} \mathrm{~ms}^{2}\right)=\left(1 / \mathrm{U}^{2} \rho\right)
$$

Free length $\left(\mathbf{L}_{\mathrm{f}}\right)$ : The free length has been calculated using the following formula given by Jacobson:

$$
\mathrm{L}_{\mathrm{f}}(\AA)=\mathrm{K} /(\mathrm{Up})^{1 / 2}
$$

where $\mathrm{K}$ is the Jacobson's constant. This constant is a temperature dependent parameter. At any temperature $(\mathrm{T})$ in Kelvin scale the value of $\mathrm{K}$ is given as $(93.875+0.345 \mathrm{~T}) \times 10^{-8}$.

Lenard jones potential (LJP): The Lenard Jones potential is given by:

$$
\mathrm{LJP}=\left[6 \mathrm{~V}_{\mathrm{m}} / \mathrm{V}_{\mathrm{a}}\right]-13
$$

where $\mathrm{V}_{\mathrm{m}}$ represents the molar volume and $\mathrm{V}_{\mathrm{a}}$ the available volume.

Internal pressure $\left(\pi_{\mathrm{i}}\right)$ : A simple equation relation using measurable parameter were

$$
\pi_{\mathrm{i}}=\mathrm{bRT}\left(\frac{\mathrm{K} \eta}{\mathrm{U}}\right)^{1 / 2} \times\left(\frac{\rho^{3 / 2}}{\mathrm{M}_{\mathrm{eff}}^{6 / 7}}\right) \mathrm{atm}
$$

where $b$ stands for the cubic packing factor, which is assumed to be two for liquid state including solutions, $\mathrm{K}$, the temperature independent constant, $\mathrm{R}$, the molar gas constant, $\mathrm{T}$, is the absolute temperature, $\eta$ is viscosity, $\mathrm{U}$ is the ultrasonic velocity, $\rho$ is the density in $\mathrm{Kg} \mathrm{m}^{-3}$ of the liquid or liquid mixture.

Free volume $\left(\mathbf{V}_{\mathrm{f}}\right)$ : On the basis of dimensional analysis, an expression for free volume in terms of experimentally measurable parameters like ultrasonic velocity and viscosity is obtained and it is given by

$$
\mathrm{V}_{\mathrm{f}}=\left(\frac{\mathrm{M}_{\text {eff }} \mathrm{U}}{\mathrm{K} \eta}\right)^{1 / 2} \mathrm{~m}^{3}
$$

where $\mathrm{M}_{\text {eff }}$ is the effective molecular weight, which is expressed as:

$$
\mathrm{M}_{\mathrm{eff}}=\mathrm{X}_{1} \mathrm{M}_{1}+\mathrm{X}_{2} \mathrm{M}_{2}+\mathrm{X}_{3} \mathrm{M}_{3}
$$

where $X_{1}$ and $M_{1}$ are the mole-fraction and molecular weight of the component in the mixture respectively. $\mathrm{K}$ is the temperature independent constant and the value of $\mathrm{K}$ is $4.28 \times 10^{9}$ and $\eta$ is the viscosity coefficient of the solution.

Cohesive energy (CE): Cohesive energy is usually given as a product of internal pressure and molar volume $\left(\mathrm{V}_{\mathrm{m}}\right)$.

Available volume $\left(\mathrm{V}_{\mathrm{a}}\right)$ : The following relation is used for available volume:

$$
\mathrm{V}_{\mathrm{a}}=\mathrm{Vm}\left(1-\frac{\mathrm{U}}{\mathrm{U}_{\infty}}\right) \mathrm{m}^{3}
$$

where $\rho$ the density of the liquid, $\mathrm{Vm}$ represents the molar volume, $\mathrm{U}$ the ultrasonic velocity and $\mathrm{U}_{\infty}$ is limiting value taken as $1600 \mathrm{~m} \mathrm{~s}^{-1}$ for liquids.

\section{RESULTS AND DISCUSSION}

Dimethyl sulphoxide (DMSO) is an effective solvent and widely used for the synthesis of organic compounds. Compounds which contain amide moieties (urea, acetamide, semi and thiosemicarbazide, phenyl urea) are easily soluble in water. But, in some synthesis water may not be used as a solvent because of several reasons. In such cases, DMSO is used instead of water. This colourless liquid is an important polar aprotic solvent that dissolves both polar and non-polar compounds and is miscible in a wide range of organic solvents as well as water. Through oxygen it may have the chances to form hydrogen bonding with other molecules. Keeping in this view, binary liquid mixture containing DMSO and MPH/MTN at five different concentrations was prepared and the parameters were studied at three different temperatures.

The experimental results of ultrasonic velocity (U), density $(\rho)$, viscosity $(\eta)$, adiabatic compressibility $(\kappa)$, intermolecular free length $\left(\mathrm{L}_{\mathrm{f}}\right)$, molar volume $\left(\mathrm{V}_{\mathrm{m}}\right)$, relaxation time $(\tau)$, specific acoustic impedance (Z), Lenard Jones potential (LJP), internal pressure $\left(\pi_{\mathrm{i}}\right)$, free volume $\left(\mathrm{V}_{\mathrm{f}}\right)$ and molecular cohesive energy (MCE), available volume $\left(\mathrm{V}_{\mathrm{a}}\right)$, Gibbs free energy $(\Delta \mathrm{G})$ and absorption coefficient $\left(\alpha / \mathrm{f}^{2}\right)$ are presented in Table-1.

Velocity: From the Table-1, for both the samples it has been observed that, as the concentration increases, velocity decreases. This decrease in velocity is due to increased association between the solute and the solvent molecules. The compounds MPH and MTN have NH-CO-NH arrangement, 


\begin{tabular}{|c|c|c|c|c|c|c|c|c|c|}
\hline \multicolumn{10}{|c|}{$\begin{array}{l}\text { MEASURED VALUE OF ULTRASONIC VELOCITY (U), DENSITY }(\rho) \text { AND VISCOSITY COEFFICIENT }(\eta) \text { OF } \\
\text { THE TWO BINARY SYSTEMS OF AQUEOUS MPH AND MTN iN DMSO AT DIFFERENT TEMPERATURES }\end{array}$} \\
\hline \multirow{2}{*}{$\begin{array}{c}\text { Conc. } \\
\left(\mathrm{mol} \mathrm{dm}^{-3}\right)\end{array}$} & \multicolumn{3}{|c|}{ Velocity $\left(\mathrm{m} \mathrm{s}^{-1}\right)$} & \multicolumn{3}{|c|}{ Density $\left(\mathrm{kg} \mathrm{m}^{-3}\right)$} & \multicolumn{3}{|c|}{ Viscosity $\left(\times 10^{3} \mathrm{~N} \mathrm{~m} \mathrm{~s}^{-1}\right)$} \\
\hline & $303 \mathrm{~K}$ & $308 \mathrm{~K}$ & $313 \mathrm{~K}$ & $303 \mathrm{~K}$ & $308 \mathrm{~K}$ & $313 \mathrm{~K}$ & $303 \mathrm{~K}$ & $308 \mathrm{~K}$ & $313 \mathrm{~K}$ \\
\hline \multicolumn{10}{|c|}{ 2-[(Morpholin-4-yl)(pyridin-3-yl)methyl]hydrazinecarboxamide (MPH) } \\
\hline 0.001 & 1486.9 & 1458.3 & 1437.4 & 1087.8 & 1083.3 & 1079.5 & 1.5531 & 1.5190 & 1.4992 \\
\hline 0.002 & 1483.8 & 1453.0 & 1429.6 & 1086.1 & 1082.3 & 1078.1 & 1.5442 & 1.5086 & 1.4821 \\
\hline 0.003 & 1476.7 & 1448.8 & 1423.1 & 1085.2 & 1081.1 & 1077.4 & 1.5388 & 1.4931 & 1.4760 \\
\hline 0.004 & 1472.4 & 1444.6 & 1419.2 & 1084.3 & 1080.3 & 1076.1 & 1.5231 & 1.4857 & 1.4635 \\
\hline 0.005 & 1470.4 & 1440.1 & 1412.8 & 1083.8 & 1079.3 & 1075.2 & 1.5173 & 1.4744 & 1.4582 \\
\hline \multicolumn{10}{|c|}{ N-(Morpholino (thiophen-2-yl) methyl)nicotino hydrazide) (MTN) } \\
\hline 0.001 & 1517.3 & 1501.4 & 1485.5 & 1089.7 & 1084.2 & 1080.4 & 1.7708 & 1.7209 & 1.6854 \\
\hline 0.002 & 1508.5 & 1491.0 & 1480.0 & 1087.8 & 1083.2 & 1079.5 & 1.7513 & 1.6977 & 1.6623 \\
\hline 0.003 & 1497.2 & 1482.3 & 1470.3 & 1086.6 & 1082.3 & 1078.5 & 1.7276 & 1.6708 & 1.6381 \\
\hline 0.004 & 1488.6 & 1473.1 & 1457.4 & 1085.0 & 1081.1 & 1077.1 & 1.7104 & 1.6455 & 1.6122 \\
\hline 0.005 & 1478.8 & 1460.1 & 1450.0 & 1084.8 & 1080.3 & 1076.0 & 1.6801 & 1.6227 & 1.5941 \\
\hline
\end{tabular}

this may interact with solvent molecules (DMSO). This shows the existence of hydrogen bonding present in the liquid mixture. Further, it has been observed that when temperature increases velocity decreases, this may be attributed to the increased vibration or collision between the solvent and solute molecules.

Adiabatic compressibility: It has been observed from the Table-2, the adiabatic compressibility values computed for the samples at different concentrations, were found to increase as the concentration increases. This increase in concentration is due to molecular aggregation. Molecular aggregation takes place through hydrogen bonding between the solute and solvent. This result clearly reveals the existence of hydrogen bonding in the liquid mixture.

Free length $\left(\mathrm{L}_{\mathrm{f}}\right)$ : The free length $\left(\mathrm{L}_{\mathrm{f}}\right)$ values measured at different concentrations are listed in Table-2. It has been found that, $\mathrm{L}_{\mathrm{f}}$ values increases as the concentration increases. In dilute solutions, the distance between the molecules will be large. Hence, the length of the non-covalent interaction will be less. While in concentrated solutions, due to hydrogen bonding the distance between the molecules will be less. Therefore, the intermolecular free length $\left(\mathrm{L}_{\mathrm{f}}\right)$ is found to increase in both the samples.

Relaxation time $(\tau)$ : The relaxation time $(\tau)$ computed for different concentrations under different temperature for the binary liquid systems are presented in Table-3. It has been noted that the $(\tau)$ value increases with increase in concentration of the systems. The dispersion of the ultrasonic velocity in the system should contain information about characteristic time $(\tau)$ of the relaxation process that causes dispersion. The relaxation time, which is in the order of $10^{-13} \mathrm{sec}$ is due to structural relaxation process and in situation. It is suggested that the molecules get rearranged due to cooperative process.

Acoustic impedance: Acoustic impedance $(Z)$ values measured for different concentrations at three different temperatures are given in Table- 3 . The result shows that for both the samples, the $\mathrm{Z}$ value decreases with increase in concentration of the system. Similar trend was observed for both the samples when the temperature increases.

Free volume: Free volume is one of the significant factors in explaining the variations in the physico-chemical properties of liquid mixture. The free space and its dependent properties have a close connection with molecular structure and it may show interesting features about interactions. This molecular interactions between like and unlike molecules are influenced by structural arrangements along with the shape and size of the molecules. From the results of computed values of free volume of the binary liquid mixture at different concentrations, it has been observed that there is an increase in free volume as concentration increases. This increase in free volume is attributed to the strong interaction between the molecules when

TABLE-2

COMPUTED VALUES OF ADIABATIC COMPRESSIBILITY ( $\kappa)$, INTERMOLECULAR FREE LENGTH $\left(\mathrm{L}_{\mathrm{f}}\right)$, MOLAR $\operatorname{VOLUME}\left(\mathrm{V}_{\mathrm{m}}\right)$ of TWO BINARY SYSTEMS OF MPH AND MTN AT DIFFERENT TEMPERATURES

\begin{tabular}{|c|c|c|c|c|c|c|c|c|c|}
\hline \multirow{2}{*}{$\begin{array}{c}\text { Conc. } \\
\left(\mathrm{mol} \mathrm{dm}^{-3}\right)\end{array}$} & \multicolumn{3}{|c|}{ Adiabatic compressibility $\left(\times 10^{-10} \mathrm{~m}^{2} \mathrm{~N}^{-1}\right)$} & \multicolumn{3}{|c|}{ Free length $\left(\times 10^{-10} \mathrm{~m}\right)$} & \multicolumn{3}{|c|}{ Molar volume $\left(\times 10^{-7} \mathrm{~m}^{3} \mathrm{~mol}^{-1}\right)$} \\
\hline & $303 \mathrm{~K}$ & $308 \mathrm{~K}$ & $313 \mathrm{~K}$ & $303 \mathrm{~K}$ & $308 \mathrm{~K}$ & $313 \mathrm{~K}$ & $303 \mathrm{~K}$ & $308 \mathrm{~K}$ & $313 \mathrm{~K}$ \\
\hline \multicolumn{10}{|c|}{ 2-[(Morpholin-4-yl)(pyridin-3-yl)methyl]hydrazinecarboxamide (MPH) } \\
\hline 0.001 & 0.415 & 0.434 & 0.448 & 0.4231 & 0.4362 & 0.4473 & 1.6638 & 1.6707 & 1.6765 \\
\hline 0.002 & 0.418 & 0.437 & 0.453 & 0.4243 & 0.4380 & 0.4500 & 1.6741 & 1.6799 & 1.6865 \\
\hline 0.003 & 0.422 & 0.440 & 0.458 & 0.4265 & 0.4395 & 0.4522 & 1.6833 & 1.6897 & 1.6955 \\
\hline 0.004 & 0.425 & 0.443 & 0.461 & 0.4279 & 0.4409 & 0.4537 & 1.6924 & 1.6987 & 1.7053 \\
\hline 0.005 & 0.426 & 0.446 & 0.465 & 0.4286 & 0.4425 & 0.4560 & 1.7009 & 1.7080 & 1.7145 \\
\hline \multicolumn{10}{|c|}{ N-(Morpholino (thiophen-2-yl) methyl)nicotino hydrazide) (MTN) } \\
\hline 0.001 & 0.3986 & 0.4092 & 0.4194 & 0.4143 & 0.4235 & 0.4326 & 1.6609 & 1.6694 & 1.6753 \\
\hline 0.002 & 0.4039 & 0.4153 & 0.4229 & 0.4171 & 0.4266 & 0.4344 & 1.6716 & 1.6787 & 1.6845 \\
\hline 0.003 & 0.4105 & 0.4205 & 0.4289 & 0.4204 & 0.4293 & 0.4375 & 1.6814 & 1.6881 & 1.6940 \\
\hline 0.004 & 0.4159 & 0.4263 & 0.4371 & 0.4232 & 0.4322 & 0.4416 & 1.6916 & 1.6977 & 1.7041 \\
\hline 0.005 & 0.4215 & 0.4342 & 0.4420 & 0.4260 & 0.4362 & 0.4441 & 1.6997 & 1.7068 & 1.7136 \\
\hline
\end{tabular}




\begin{tabular}{|c|c|c|c|c|c|c|c|c|c|}
\hline \multirow{3}{*}{$\begin{array}{l}\text { Conc. } \\
\left.(\mathrm{mol} \mathrm{dm})^{-3}\right)\end{array}$} & \multicolumn{9}{|c|}{$\begin{array}{l}\text { OMPUTED VALUES OF RELAXATION TIME }(\tau) \text {, SPECIFIC ACOUSTIC IMPEDANCE }(Z) \text { AND LENARD JONES } \\
\text { POTENTIAL (LJP) OF TWO BINARY SYSTEMS OF MPH AND MTN AT DIFFERENT TEMPERATURES }\end{array}$} \\
\hline & \multicolumn{3}{|c|}{ Relaxation time $\left(\times 10^{-13} \mathrm{~s}\right)$} & \multicolumn{3}{|c|}{$\begin{array}{l}\text { Specific acoustic impedance } \\
\left(\times 10^{3} \mathrm{Kg}^{-1} \mathrm{~m}^{2} \mathrm{~s}^{-1}\right)\end{array}$} & \multicolumn{3}{|c|}{$\mathrm{LJP}\left(\mathrm{J} \mathrm{mol}^{-1}\right)$} \\
\hline & $303 \mathrm{~K}$ & $308 \mathrm{~K}$ & $313 \mathrm{~K}$ & $303 \mathrm{~K}$ & $308 \mathrm{~K}$ & $313 \mathrm{~K}$ & $303 \mathrm{~K}$ & $308 \mathrm{~K}$ & $313 \mathrm{~K}$ \\
\hline \multicolumn{10}{|c|}{ 2-[(Morpholin-4-yl)(pyridin-3-yl)methyl]hydrazinecarboxamide (MPH) } \\
\hline 0.001 & 8.6104 & 8.7913 & 8.9623 & 1.6174 & 1.5797 & 1.5516 & 71.88 & 54.74 & 46.04 \\
\hline 0.002 & 8.6104 & 8.8031 & 8.9686 & 1.6115 & 1.5725 & 1.5412 & 69.61 & 52.30 & 43.33 \\
\hline 0.003 & 8.6701 & 8.7729 & 9.0193 & 1.6025 & 1.5662 & 1.5332 & 64.85 & 50.49 & 41.26 \\
\hline 0.004 & 8.6391 & 8.7868 & 9.0030 & 1.5965 & 1.5606 & 1.5272 & 62.23 & 48.77 & 40.09 \\
\hline 0.005 & 8.6336 & 8.7827 & 9.0595 & 1.5936 & 1.5543 & 1.5190 & 61.07 & 47.03 & 38.28 \\
\hline \multicolumn{10}{|c|}{ N-(Morpholino (thiophen-2-yl) methyl)nicotino hydrazide) (MTN) } \\
\hline 0.001 & 9.4115 & 9.3884 & 9.4257 & 1.6534 & 1.6278 & 1.6049 & 103.0 & 84.36 & 70.84 \\
\hline 0.002 & 9.4332 & 9.4002 & 9.3735 & 1.6409 & 1.6150 & 1.5976 & 91.91 & 75.07 & 67.00 \\
\hline 0.003 & 9.4570 & 9.3679 & 9.3680 & 1.6268 & 1.6042 & 1.5857 & 80.38 & 68.56 & 61.01 \\
\hline 0.004 & 9.4853 & 9.3520 & 9.3960 & 1.6151 & 1.5925 & 1.5697 & 73.17 & 62.65 & 54.32 \\
\hline 0.005 & 9.4429 & 9.3944 & 9.3950 & 1.6042 & 1.5773 & 1.5600 & 66.20 & 55.62 & 51.00 \\
\hline
\end{tabular}

the solute concentration increases. Free volume values measured for different concentrations at three different temperatures are presented in Table-4.
Enthalpy: The measured values of enthalpy for the binary liquid mixtures of two samples are shown in Fig. 1. As the concentration of the solute increases, the enthalpy is found to

\begin{tabular}{|c|c|c|c|c|c|c|c|c|c|}
\hline & & & & \multicolumn{4}{|c|}{$\begin{array}{l}\text { COMPUTED VALUES OF INTERNAL PRESSURE }\left(\pi_{\mathrm{i}}\right) \text {, FREE VOLUME }\left(V_{\mathrm{f}}\right) \text { AND MOLECULAR COHESIVE } \\
\text { ENERGY (MCE) OF TWO BINARY SYSTEMS OF MPH AND MTN AT DIFFERENT TEMPERATURES }\end{array}$} & $\begin{array}{l}\text { HESIVI } \\
\text { URES }\end{array}$ & \\
\hline \multirow{2}{*}{$\begin{array}{c}\text { Conc. } \\
\left(\mathrm{mol} \mathrm{dm}^{-3}\right)\end{array}$} & \multicolumn{3}{|c|}{ Internal pressure $\left(\times 10^{-6}\right)$} & \multicolumn{3}{|c|}{ Free volume $\left(\times 10^{-6} \mathrm{~m}^{3} \mathrm{~mol}^{-1}\right)$} & \multicolumn{3}{|c|}{ Enthalpy $\left(\times 10^{-9} \mathrm{KJ}\right)$} \\
\hline & $303 \mathrm{~K}$ & $308 \mathrm{~K}$ & $313 \mathrm{~K}$ & $303 \mathrm{~K}$ & $308 \mathrm{~K}$ & $313 \mathrm{~K}$ & $303 \mathrm{~K}$ & $308 \mathrm{~K}$ & $313 \mathrm{~K}$ \\
\hline \multicolumn{10}{|c|}{ 2-[(Morpholin-4-yl)(pyridin-3-yl)methyl]hydrazinecarboxamide (MPH) } \\
\hline 0.001 & 38421 & 38893 & 39458 & 8.1457 & 8.1798 & 8.1637 & 63.92 & 64.97 & 66.15 \\
\hline 0.002 & 38105 & 38598 & 39094 & 8.2475 & 8.2766 & 8.2951 & 63.79 & 64.84 & 65.93 \\
\hline 0.003 & 37901 & 38217 & 38872 & 8.2895 & 8.4284 & 8.3481 & 63.80 & 64.57 & 65.91 \\
\hline 0.004 & 37541 & 37956 & 38524 & 8.4388 & 8.5126 & 8.4784 & 63.53 & 64.47 & 65.69 \\
\hline 0.005 & 37285 & 37647 & 38316 & 8.5278 & 8.6290 & 8.5249 & 63.42 & 64.30 & 65.69 \\
\hline \multicolumn{10}{|c|}{ N-(Morpholino (thiophen-2-yl) methyl)nicotino hydrazide) (MTN) } \\
\hline 0.001 & 40658 & 40819 & 41174 & 6.8974 & 7.0867 & 7.1959 & 67.53 & 68.14 & 68.97 \\
\hline 0.002 & 40284 & 40439 & 40723 & 7.0008 & 7.2076 & 7.3569 & 67.34 & 67.88 & 68.59 \\
\hline 0.003 & 39911 & 39992 & 40311 & 7.1154 & 7.3698 & 7.4996 & 67.10 & 67.50 & 68.28 \\
\hline 0.004 & 39575 & 39569 & 39918 & 7.2104 & 7.5221 & 7.6327 & 66.94 & 67.17 & 68.02 \\
\hline 0.005 & 39138 & 39239 & 39555 & 7.3839 & 7.6320 & 7.7571 & 66.52 & 66.97 & 67.78 \\
\hline
\end{tabular}
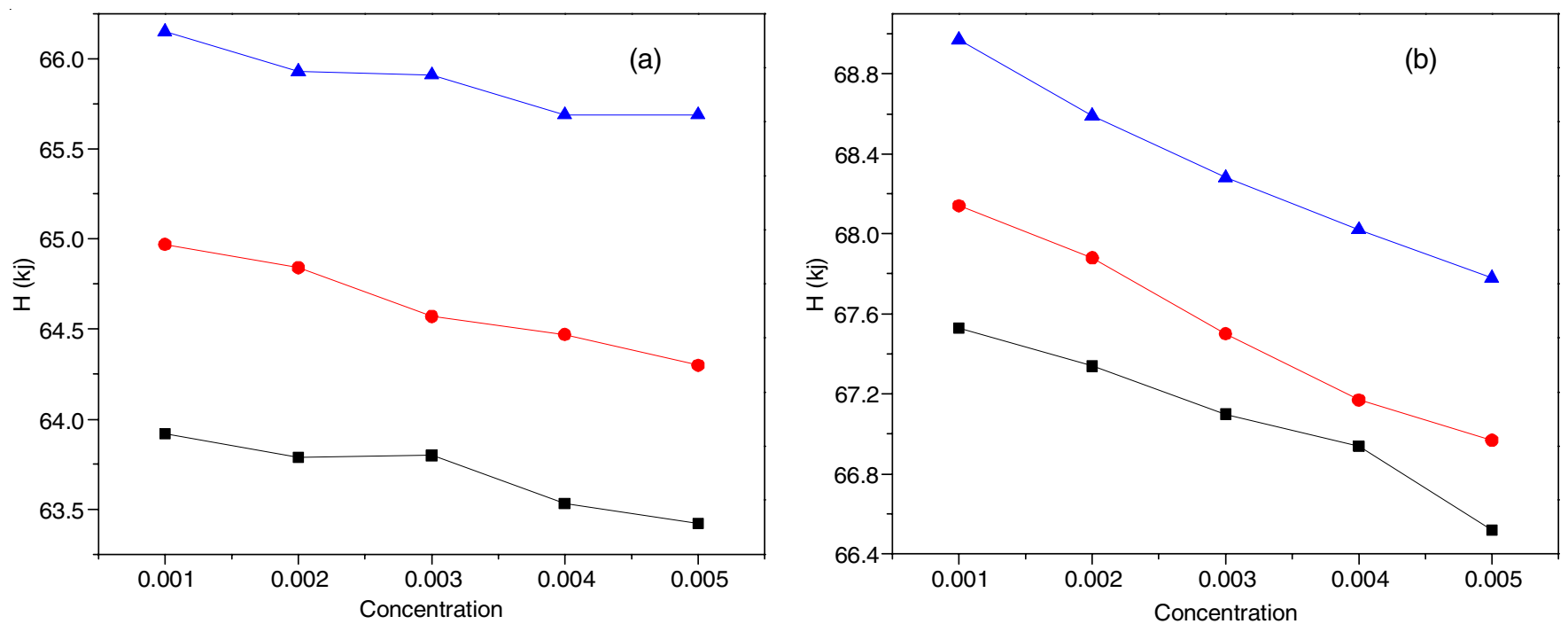

Fig. 1. Plots for enthalpy versus concentration for aqueous (a) MPH and (b) MTN at different temperatures ( $\bullet$ ) T = $303 \mathrm{~K}$, ( $\bullet$ ) $308 \mathrm{~K}$ and ( $\boldsymbol{\Delta}$ ) $313 \mathrm{~K}$ 

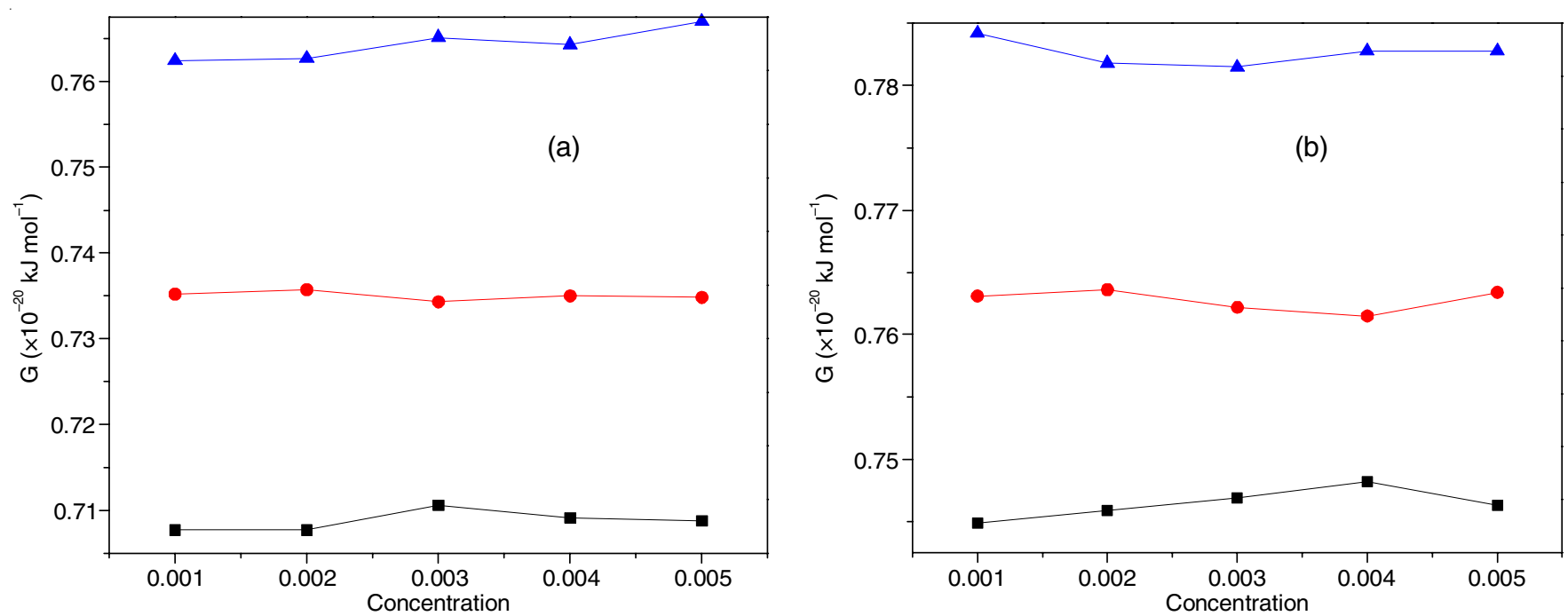

Fig. 2. Plots for Gibbs free energy versus concentration for aqueous (a) MPH and (b) MTN at different temperatures ( $\bullet$ ) T = $303 \mathrm{~K}$, ( $\bullet$ ) 308 $\mathrm{K}$ and ( $\mathbf{\Delta}) 313 \mathrm{~K}$

increase. The same trend has been observed when the temperature of the system increases.

Gibb's free energy: The computed values of Gibb's free energy for the binary liquid mixture of two samples are shown in Fig. 2. From the results, it has been understood that the $(\Delta \mathrm{G})$ decreases with increase in concentration of the system. This decrease in free energy confirms the formation of hydrogen bonding in binary mixtures.

The excess properties derived from these physical property data reflect the physico-chemical behaviour of the liquid mixtures with respect to the solution, structure and intermolecular interactions between the component molecules of the mixture. The trends of changes have been interpreted by the earlier works reported by various researchers [22,23]. It was revealed from the literature, that the trends of changes mainly depend on the differences in the size of the molecule and strength of interactions taking place between the components of the mixtures. The velocity of sound through liquid mixtures could be helpful in assessing the degree of association between the molecules. The molar sound velocity on non-associated liquids has been found to be independent, while that for associated liquids is dependent on temperature.

\section{Conclusion}

The ultrasonic velocity, adiabatic compressibility, free length, viscosity, free volume, free length, molar volume, density, internal pressure, free energy and enthalpy have been measured. The measured value of ultrasonic velocity, internal pressure, enthalpy and free energy was found to increase as the concentration increases. The calculated values of adiabatic compressibility were found to decrease as the concentration increases. These results are inferred that strong interaction exists between the solvent (DMSO) and the solute (MPH and MTN). Hence it is concluded that the association of solute molecules occurs through hydrogen bonding.

\section{ACKNOWLEDGEMENTS}

The authors are thankful to the College Management Committee and Principal for the support during this research work.

\section{CONFLICT OF INTEREST}

The authors declare that there is no conflict of interests regarding the publication of this article.

\section{REFERENCES}

1. Sk.M. Nayeem, M. Kondaiah, K. Sreekanth and D.K. Rao, J. Appl. Chem., 2014, Article ID 741795 (2014);

https://doi.org/10.1155/2014/741795.

2. G.V. Ramarao, V.A. Sharma, D. Ramachandran and C. Rambabu, Indian J. Chem., 46A, 1972 (2007).

3. C.D. Eads, J. Phys. Chem. B, 104, 6653 (2000); https://doi.org/10.1021/jp993472c.

4. V. Kannappan and R. Jaya Shanthi, Indian J. Pure Appl. Phys., 43, 750 (2005).

5. V. Kannappan, S.X.J. Raja and R. Jaya Santhi, Indian J. Pure Appl. Phys., 41, 690 (2003).

6. S. Jayakumar, N. Karunanithi, V. Kannappan and S. Gunasekaran, Asian Chem. Lett., 3, 224 (1999).

7. V. Kannappan and R. Jaya Santhi, J. Acous. Soc. Indian, 29, 192 (2001).

8. S.K. Dash and B.B. Swain, Chem. Pap., 48, 146 (1994).

9. S.K. Dash, V. Chakravorthy and B.B. Swain, Acoust. Lett., 19, 142 (1996).

10. P.S. Nikam, T.R. Mahale and M. Hasan, J. Acoustica Acta, 84, 579 (1998).

11. P.S. Nikam, M.C. Jadhav and M.J. Hasan, J. Mol. Liq., 76, 1 (1998); https://doi.org/10.1016/S0167-7322(97)00051-2.

12. V. Kannappan, R. Jaya Santhi and S.X.J. Raja, Phys. Chem. Liq., 41, 133 (2003); https://doi.org/10.1080/0031910031000079295.

13. U. Srinivasalu and P. Ramachandra Naidu, J. Pure Appl. Ultrason., 17, 14 (1995).

14. A.N. Kannappan and L. Palaniappan, Indian J. Phys., 73B, 531 (1999).

15. U. Sridevi, K. Samatha and A. Visvanantasarma, J. Pure Appl. Ultrason., 26, 1 (2004).

16. A. Ali, S. Hydar and A.K. Nain, Indian J. Phys., 74B, 63 (2000).

17. S.L. Oswal, P. Oswal and J.P. Dave, J. Mol. Liq., 94, 203 (2001); https://doi.org/10.1016/S0167-7322(01)00269-0.

18. S.L. Oswal, R.L. Gardas and R.P. Phalak, J. Mol. Liq., 116, 109 (2005); https://doi.org/10.1016/j.molliq.2004.07.081.

19. V. Kannappan, R. Jaya Santhi and E.J.P. Malar, Phys. Chem. Liq., 40, 507 (2002); https://doi.org/10.1080/00319100290010437.

20. V.A. Tabhane, A. Sangeeta and K.G. Revetkar, J. Acous. Soc. India, 8, 369 (2000).

21. A. Anwar and K.N. Anil, Acoust. Lett., 19, 181 (1996).

22. S. Thirumaran, J.E. Jayakumar and B.H. Dhanasundaram, E-J. Chem., 7, 465 (2010); https://doi.org/10.1155/2010/735216.

23. S. Thirumaran, M. Suguna and S.R. Selvi, Res. J. Chem. Environ., 13, 81 (2009). 